\title{
EFEITO DA ELETRODEPOSIÇÃO DE NÍQUEL-NIÓBIO NO COMPORTAMENTO EM FADIGA DE UM AÇO SAE 1020*
}

\author{
Isadora Pereira Nunes ${ }^{1}$ \\ Ricardo Luiz Perez Teixeira² \\ Valdir Tesche Signoretti ${ }^{3}$ \\ José Carlos de Lacerda ${ }^{4}$
}

\section{Resumo}

O objetivo deste trabalho é estudar o efeito do recobrimento de níquel-nióbio por eletrodeposição na resistência à fadiga de um aço carbono SAE 1020. Os corpos de prova para os ensaios de fadiga foram extraídos de barras de diâmetro igual a 7,94 $\mathrm{mm}$ (5/16"). Os ensaios de fadiga foram realizados por flexão rotativa com carregamento em balanço. Foi empregada uma velocidade de rotação de aproximadamente 1500rpm. Foram realizados ensaios de dureza do aço e da camada depositada de $\mathrm{Ni}-\mathrm{Nb}$. Análises microestruturais do aço e das fraturas de fadiga foram realizadas através de microscopia eletrônica de varredura (MEV). Os ensaios de fadiga foram realizados de forma a se obter curvas S-N (curvas de Whöler). Foram realizados três ensaios para cada carregamento. Foi observado que o recobrimento de $\mathrm{Ni}-\mathrm{Nb}$ proporcionou tendência ao aumento do limite de resistência à fadiga do aço. Palavras-chave: Resistência à fadiga; Curva S-N; Eletrodeposição de Ni-Nb.

\section{EFFECT OF NICKEL-NIOBIUM COATING BY ELECTRODEPOSITION IN THE FATIGUE BEHAVIOR OF A SAE 1020 STEELL}

\section{Abstract}

The objective of this work is to study the effect of coating nickel-niobium by electrodeposition on the fatigue strength of a carbon steel SAE 1020. The samples for fatigue testing were carried out from bars diameter $7.94 \mathrm{~mm}$. The fatigue tests were performed by bending with rotary loading balance. The tests were performed with 1500rpm. Hardness tests were conducted on the steel and deposited Ni-Nb coating. Microstructural analysis of the steel and fatigue fractures were performed by scanning electron microscopy (SEM). The fatigue tests were performed to obtain Whöler curves. Three tests were performed for each loading. It was observed that $\mathrm{Ni}-\mathrm{Nb}$ coating provided a small increase on the fatigue strength of the steel.

Keywords: Fatigue strength; S-N curves; Electrodeposition of Ni-Nb.

1 Pesquisadora do Curso de Engenharia de Materiais; UNIFEl; Isadora.nunes.08@gmail.com

2 Membro da ABM; Engenheiro Químico; Doutor em Ciências, Engenharia Metalúrgica e de Materiais; Professor da Universidade Federal de Itajubá, Campus Itabira, Itabira, MG-Brasil, ricardo.luiz@unifei.edu.br.

3 Engenheiro Químico; Doutor em Engenharia Mecânica; Professor da Universidade Federal de Itajubá, Campus Itabira, Itabira, MG-Brasil, valdirsignoretti@unifei.edu.br

4 Membro da ABM; Engenheiro Mecânico, Doutor em Engenharia de Materiais; Professor da Universidade Federal de Itajubá, Campus Itabira, Itabira, MG-Brasil, jlacerda.cem@gmail.com. 


\section{INTRODUÇÃO}

A fadiga é um fenômeno que ocorre em estruturas que estão sujeitas a tensões dinâmicas. Estes tipos de tensões podem estar presentes em elementos de máquinas em geral, peças de automóveis e de aeronaves. Grande atenção deve ser dada às possibilidades de falhas por fadiga tendo em vista que essas podem ocorrer de forma catastrófica. Geralmente, falhas de fadiga ocorrem de forma brusca e em níveis de tensões consideravelmente abaixo do limite de resistência estático do material. Outro aspecto importante a ser considerado em relação à fadiga é que à ela pode ser atribuída aproximadamente $90 \%$ de todas as falhas ocorridas em componentes mecânicos [1,2].

Há uma série de fatores que podem afetar o comportamento em fadiga de um material: acabamento superficial, distribuição de inclusões, tamanho de grão e sua morfologia, tipo ou tamanho de corpo de prova, tipo de carregamento, temperatura, condições do meio e finalmente, tratamento e recobrimento superficial, que será o principal objeto de investigação neste trabalho [2]. Todos estes fatores, direta ou indiretamente, poderão afetar uma pequena faixa na superfície do material onde na maioria dos casos se nucleiam trincas de fadiga. Nessa faixa superficial do material, com o carregamento cíclico, há o surgimento das denominadas bandas de deslizamento persistentes (PSBs - Persistent Slip Bands) que dão origem às intrusões e extrusões superficiais. Estas intrusões e extrusões geradas propiciam a criação de micro concentradores de tensão a partir dos quais é favorecida a nucleação de trincas que se propagam pelo material até o seu colapso final $[1,3]$.

Nesse trabalho foi dada ênfase à investigação do efeito de recobrimento superficial no comportamento em fadiga de um aço carbono SAE 1020. Foram realizados recobrimentos de Ni-Nb por eletrodeposição. Recobrimentos de $\mathrm{Ni}$ em aço carbono produzem considerável melhora do limite de fadiga, principalmente quando se tem algum tratamento posterior à eletrodeposição para a eliminação de eventuais tensões superficiais [2]. A adição de partículas de $\mathrm{Nb}$ ao banho eletrolítico de níquel Watts produz recobrimento de níquel metálico com a presença de particulados de nióbio que concorrem para aumento da dureza superficial [4-6]. Aumento de dureza superficial está correlacionado com aumento de resistência à fadiga [2], daí o recobrimento de $\mathrm{Ni}$-Nb ser favorável à melhora dessa propriedade do aço $[7,8]$.

\section{MATERIAIS E MÉTODOS}

Foram usinados 20 corpos de provas de $8 \mathrm{~mm}$ de diâmetro e $380 \mathrm{~mm}$ de comprimento para os ensaios de fadiga. Os corpos de prova foram usinados de acordo com a norma ASTM E466, 1996.

Cada corpo de prova usinado passou por um processo de eletrodeposição de $\mathrm{Ni}-\mathrm{Nb}$ realizado através do banho de níquel Watts com adição de $40 \mathrm{~g} / \mathrm{l}$ de nióbio, cujas partículas apresentavam diâmetro médio de $174,23 \mu \mathrm{m}$. Para o banho eletrolítico, foi utilizada uma fonte marca INSTUTHERM, modelo DC POWER SUPPLY FA-3030 e um agitador magnético marca BIOMIXER, modelo 78HW-1. A composição do banho de níquel Watts é apresentada na Tabela 1 [4].O tempo total de cada eletrodeposição foi de 3horas. O banho foi submetido à agitação através de agitador magnético (aproximadamente $600 \mathrm{rpm}$ ) e a temperatura aplicada foi de $60^{\circ} \mathrm{C}$. $\mathrm{O} \mathrm{pH}$ da solução foi mantido em torno de 3,5. Foi utilizado um eletrodo de níquel como anodo e o catodo foi o próprio substrato de aço SAE 1020 (corpo de prova). A corrente aplicada foi de 
$11 \mathrm{~mA}$ para uma área do substrato de $0,0283 \mathrm{dm}^{2}\left(0,4 \mathrm{~A} / \mathrm{dm}^{2}\right)$ e a voltagem foi mantida em $2,7 \mathrm{~V}$.

Tabela 1. Relação dos reagentes utilizados no Banho de Watts [4]

\begin{tabular}{cccc}
\hline Reagentes & $\begin{array}{c}\text { Pureza } \\
(\%)\end{array}$ & $\begin{array}{c}\text { Concentração } \\
(\mathbf{m o l} / \mathbf{L})\end{array}$ & Massa (g) \\
\hline $\mathrm{NiSO}_{4}$ & 98,0 & 0,22 & 118,02 \\
\hline $\mathrm{H}_{2} \mathrm{BO}_{3}$ & 99,5 & 0,13 & 33,00 \\
\hline $\mathrm{ZnSO}_{4}$ & 96,0 & 0,55 & 330,00 \\
\hline $\mathrm{NiCl}_{2}$ & 98,0 & 0,33 & 106,21 \\
\hline Sorbitol & 70,00 & 0,39 & $134,0(90 \mathrm{ml})$ \\
\hline
\end{tabular}

Após a etapa de recobrimento, cada corpo de prova foi submetido a ensaios de fadiga em uma máquina de flexão rotativa, marca Edibon, em diferentes tensões numa rotação aproximada de 1500rpm, a fim de se obter a curva S-N (curva de Wöller). O carregamento adotado nessa máquina é do tipo carga em balanço, onde o carregamento ocorre em apenas uma das extremidades do corpo de prova.

Medidas de microdureza Vickers foram realizadas no aço SAE 1020 (sem recobrimento) e na camada de recobrimento de $\mathrm{Ni}-\mathrm{Nb}$ no aço. Os ensaios foram realizados em um microdurômetro Wilson Instruments, modelo 402 MVD, e os ensaios foram realizados de acordo com a norma ABNT NBR NM ISO 6567-1: 2008.

Por fim, análises das fraturas de fadiga foram realizadas em Microscópio Eletrônico de Varredura (MEV). Nessas foram identificadas as regiões de início, propagação e ruptura final da trinca.

\section{RESULTADOS E DISCUSSÃO}

\section{1- Ensaios de Microdureza}

Foram realizadas quatro medições de microdureza Vickers no substrato (aço SAE 1020) e na camada de $\mathrm{Ni}-\mathrm{Nb}$ eletrodepositada, tendo sido obtidos, respectivamente, os seguintes resultados: $194 \pm 6 \mathrm{HV}$ e $500 \pm 33 \mathrm{HV}$. Os ensaios de microdureza foram realizados com a aplicação de $0,5 \mathrm{Kgf}$ por 10 segundos.

Como relatado, houve significativo aumento da microdureza superficial do aço SAE 1020 recoberto com $\mathrm{Ni}-\mathrm{Nb}$ em relação ao mesmo aço sem recobrimento. Esse resultado está de acordo com Fratari $[9,10]$.

Variações de dureza observadas no recobrimento de $\mathrm{Ni}-\mathrm{Nb}$ podem ser atribuídas a uma deposição não uniforme. Essa deposição não uniforme pode ter ocorrido devido à alta granulometria das partículas de nióbio, assim como a inexistência de rotação do corpo de prova durante o processo de eletrodeposição. Menores granulometrias de nióbio aplicadas por Robin e Fratari resultaram em camadas depositadas mais homogêneas [6].

\section{2- Ensaio de Fadiga}

A carga a ser utilizada nos ensaios de fadiga bem como as dimensões dos corpos de prova, foram calculadas com base na equação de flexão rotativa (Equação 1). As variáveis da Equação 1 são assim discriminadas: $\sigma_{\max }$ - Tensão máxima na superfície devido à flexão no ponto critico do corpo de prova $\left(\mathrm{Kgf} / \mathrm{mm}^{2}\right) ; \quad P$ - Carga aplicada (Kgf); L - Distância do ponto de aplicação da carga até o ponto crítico (menor diâmetro) do corpo de prova ( $\mathrm{mm})$; $\mathrm{d}$ - Diâmetro crítico do corpo de prova $(\mathrm{mm})$. 


$$
\sigma_{\max }=\frac{P \cdot L}{0,1 \cdot d^{3}}
$$

A partir dos resultados obtidos nos ensaios de fadiga foi possível obter as curvas S-N (curvas de Wöhler) para o aço carbono SAE 1020 com e sem recobrimento de $\mathrm{Ni}-\mathrm{Nb}$, conforme se apresenta na Figura 1.

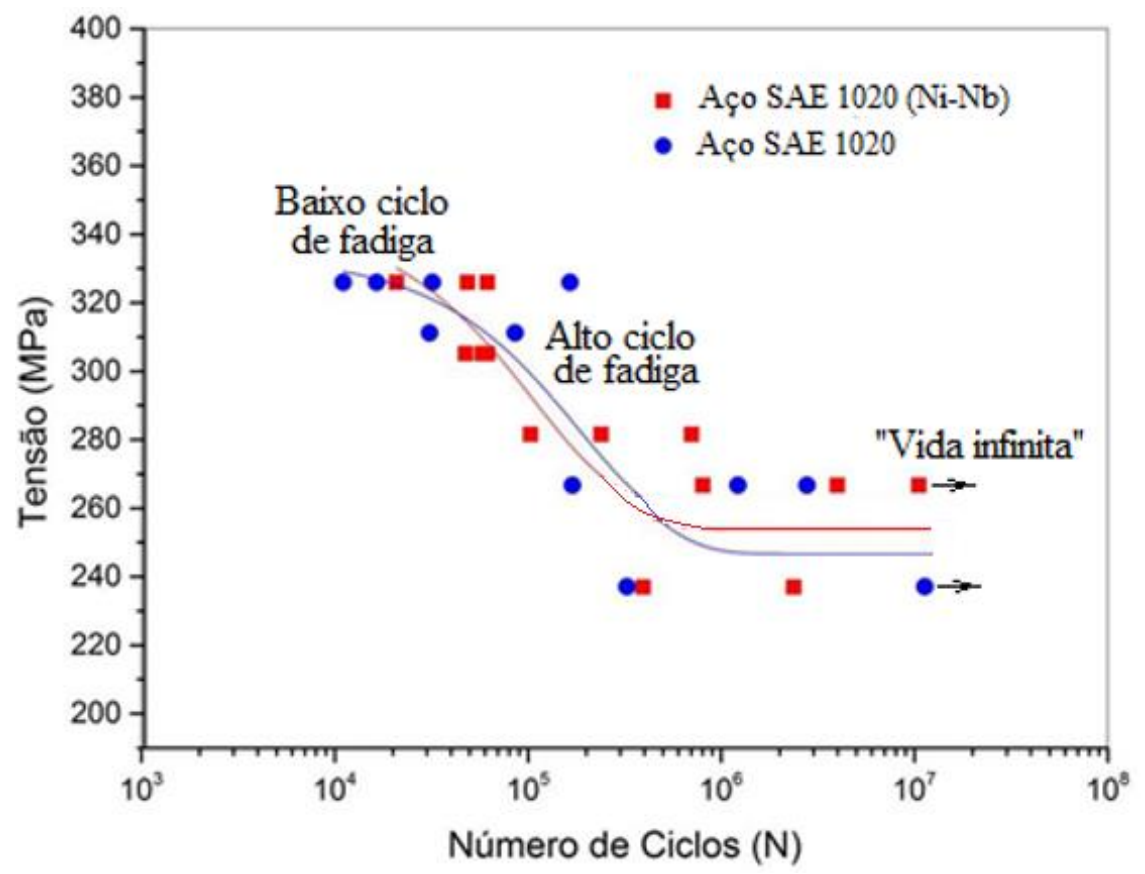

Figura 1. Curva S-N para o aço SAE 1020 com e sem recobrimento de $\mathrm{Ni}-\mathrm{Nb}$.

Conforme apresentado na Figura 1, o limite de fadiga para o aço ABNT 1020 sem recobrimento é de aproximadamente $253 \pm 12 \mathrm{MPa}$. Embora o recobrimento do aço com $\mathrm{Ni}$-Nb tenha aumentado significativamente a dureza superficial do material, como já mencionado, o limite de fadiga apresentou apenas tendência de aumento, aproximadamente $260 \pm 6 \mathrm{MPa}$. Essa constatação pode ser atribuída à deficiência na aderência do recobrimento, como pode ser observado na Figura 2 (Círculos tracejados).

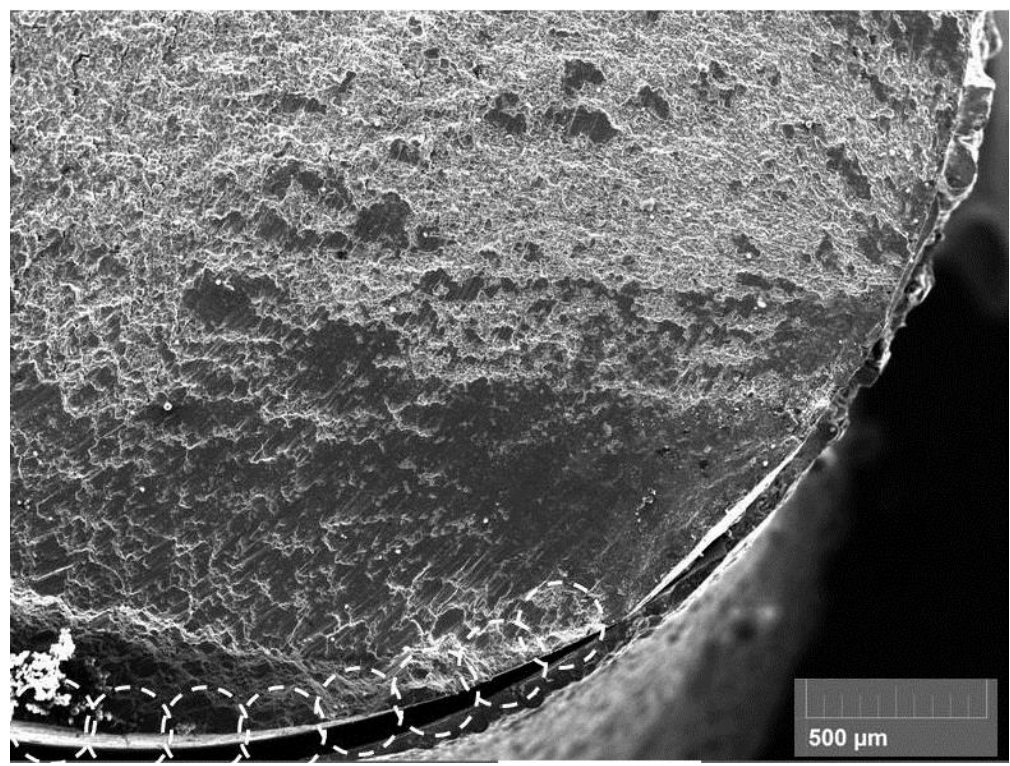

Figura 2. Fratura com descolamento do recobrimento de $\mathrm{Ni}-\mathrm{Nb}$. 


\section{3 -Microfratografias de Fadiga}

As microfratografias de fadiga foram realizadas no MEV. A fratura analisada foi relativa a uma tensão de fadiga aplicada de $281,5 \mathrm{MPa}$ cuja fratura ocorreu com 702.470 ciclos e são apresentadas nas Figuras 3 e 4. Na Figura 3 apresenta-se aspecto geral da morfologia da fratura ocorrida, com destaque para a região de nucleação da trinca (círculos tracejados), do caminho de propagação da mesma (setas) e da região de arrancamento final.

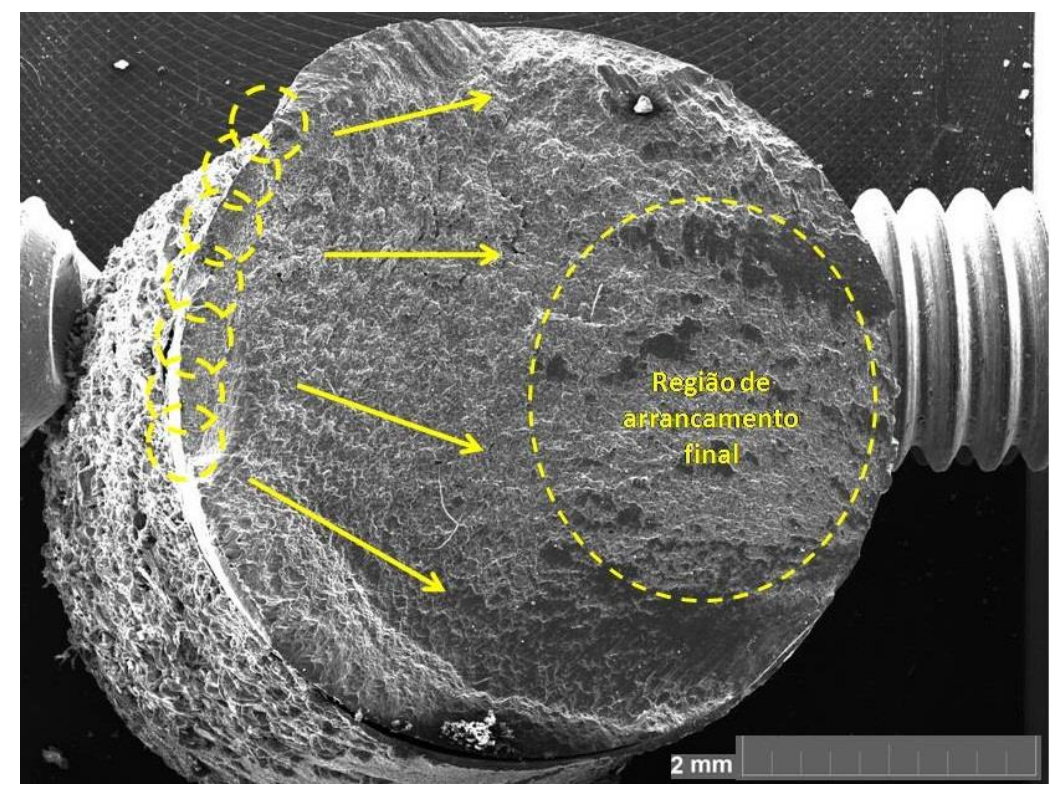

Figura 3. Microfratografia de fadiga com regiões de nucleação e propagação da trinca.

Na Figura 4 destaca-se ampliação da fratura da Figura 3 onde se apresentam estrias de fadiga, que são próprias de ocorrerem em alto ciclo de fadiga em materiais com característica dúctil.

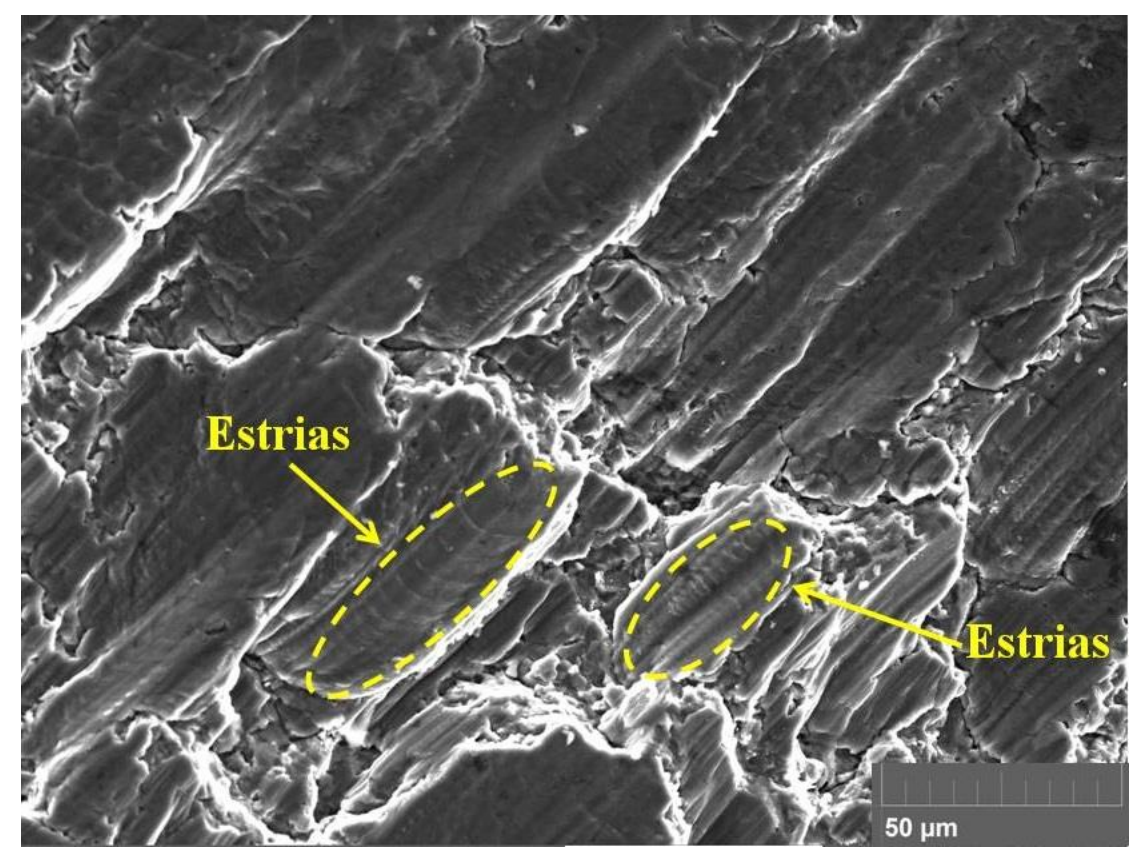

Figura 4. Microfratografia com a presença de estrias de fadiga. 


\section{CONCLUSÃO}

$>\mathrm{O}$ recobrimento de $\mathrm{Ni}-\mathrm{Nb}$ apresentou aumento considerável da dureza na superfície do aço SAE 1020 utilizado como substrato;

$>\mathrm{O}$ aumento da dureza superficial causado pelo recobrimento de $\mathrm{Ni}-\mathrm{Nb}$ revelou tendência no aumento da tensão limite de fadiga do aço SAE 1020;

$>$ Melhores resultados de fadiga poderiam ter sido obtidos com o recobrimento $\mathrm{Ni}-\mathrm{Nb}$ caso não tivesse ocorrido o descolamento da camada depositada, como observado;

$>$ O desenvolvimento de técnicas de eletrodeposição que conduzam a maior aderência da camada depositada certamente contribuirá para aumento da resistência à fadiga do aço SAE 1020.

\section{Agradecimentos}

À FAPEMIG, pelo apoio à pesquisa durante o ano de 2015. À Universidade Federal de Itajubá, Campus Itabira, pela disponibilização da infraestrutura necessária para a realização dos experimentos. Ao grupo de pesquisa GPESE (UNIFEI, Campus Itabira) pelo apoio e incentivo.

\section{REFERÊNCIAS}

1 WILLIAM, DCJR; CALLISTER, J. R. Ciência e Engenharia de Materiais: uma introdução. 5ª Edição, Editora LTC, 2008.

2 MILELLA, Pietro Paolo. Fatigue and corrosion in metals. Milan - Itália: Springer-verlag. 2013.

3 FARIA, Ricardo Augusto. Efeito dos elementos Ti e Nb no comportamento em fadiga de aços inoxidáveis ferríticos utilizados no sistema de exaustão de veículos automotores. REDEMAT. 2006.

4 DENNIS, John Keith; SUCH, Tony Eugene. Nickel and chromium plating. Elsevier, 1993.

5 DAVALOS, C. E. et al. Study of the role of boric acid during the electrochemical deposition of $\mathrm{Ni}$ in a sulfamate bath. Int J Electrochem Sci. 2013; v. 8, p. 9785.

6 ROBIN, Alain; FRATARI, R. Q. Deposition and characterization of nickel-niobium composite electrocoatings. Journal of applied electrochemistry, v. 37, n. 7, p. 805-812, 2007.

7 BANDARA, Chaminda S. et al. Fatigue failure predictions for steels in the very high cycle region-a review and recommendations. Engineering Failure Analysis, v. 45, p. 421-435, 2014.

8 SILVA, Mariana Beatriz dos Reis. Aplicação de complexos de Cull, Nill, Znll e NbV com ligantes carboxilatos em banhos de eletrodeposição. Tese de Doutorado. Universidade de São Paulo. 2009.

9 FRATARI, Rômulo Queiroz. Obtenção e Caracterização de Eletrorevestimentos Compósitos de Ni-Nb. Dissertação de Mestrado. Universidade De São Paulo. Lorena. 2005.

10 DA SILVA, Edson José. Monitoramento automático de $\mathrm{pH}$, níquel e cloretos em banhos de níquel tipo Watts utilizando um sistema SIA. Dissertação de Mestrado. Universidade Federal de Pernambuco. 2002. 